\title{
Interpreting Food Security Research Findings With Rural South African Communities
}

\author{
Angela McIntyre ${ }^{1} \&$ Sheryl Hendriks ${ }^{1}$ \\ ${ }^{1}$ Department of Agricultural Economics, Extension and Rural Development, Faculty of Natural and Agricultural \\ Sciences, University of Pretoria, South Africa \\ Correspondence: Prof. Sheryl Hendriks, Department of Agricultural Economics, Extension and Rural \\ Development, Faculty of Natural and Agricultural Sciences, University of Pretoria, Private bag X20, Hatfield 0028, \\ South Africa. E-mail: Sheryl.Hendriks@up.ac.za
}

Received: January 27, 2018 Accepted: February 20, 2018 Online Published: April 28, 2018

doi:10.5539/gjhs.v10n5p183 URL: https://doi.org/10.5539/gjhs.v10n5p183

\begin{abstract}
Introduction: The presence of concurrent childhood stunting and adult obesity observed in poor, rural, former homeland communities in South Africa appears to be explained by nutrition transition, but the factors shaping rural food security are still poorly understood. Localized constraints and capabilities are often overlooked by food security policies, strategies and programs. Grounding food security data in local contexts is often a missing step in the diagnosis of food insecurity.
\end{abstract}

Aims: This qualitative study aimed to engage members of poor rural communities in generating a more grounded, localized understanding of food insecurity.

Method: Members of South Africa's poorest rural communities were asked to validate and interpret food production, consumption and nutrition data from a three-year, multidisciplinary food security study, with the aid of graphic presentations to overcome literacy barriers.

Results: Interpretations of food security research findings by communities revealed unique local experiences and understandings of food insecurity.

Conclusion: Engaging people in the joint diagnosis of their food security challenges generates information on the environmental, economic and cultural conditions that shape experiences of hunger and influence nutrition outcomes, which are not always captured by conventional food security analyses. More inclusive and participatory research could support the design of more effective food security interventions in marginalized rural communities.

Keywords: food Security, malnutrition, obesity, stunting, agriculture, climate change, South Africa, qualitative research

\section{Introduction}

South Africa is a geographically and culturally diverse, middle-income country experiencing chronic food insecurity. While this is both a rural and urban problem, it is concentrated in rural, former homeland (native reserve) areas. Food security and social protection policies in South Africa have had some success in alleviating extreme poverty and hunger, but are failing to address chronic food insecurity in rural communities. This paper demonstrates one of the ways food insecurity be better understood through the participatory validation and interpretation of research findings. It describes facilitated discussions with rural community groups of the results of a four-year study exploring the rain-fed and irrigated small-scale production in rural, former homeland regions of South Africa, entitled "Current rain-fed and irrigated production of food crops and its potential to meet all year round nutritional requirements of rural poor people in North West, Limpopo, KwaZulu-Natal and Eastern Cape Provinces." The aim was to validate quantitative food security data and to further ground the data in communities' experiences and understandings of food production, dietary patterns and malnutrition in their own communities, giving a subjective, 'insider' perspective on the food security challenges faced by poor, rural South Africans.

South Africa's poorest rural communities show rising levels of obesity and persistent rates of childhood stunting (Shisana, et al. 2013; Steyn et al. 2005). Nationally, among women over 15 years of age $39.2 \%$ are overweight and over $24 \%$ obese, while $14 \%$ of children under nine are obese and $26.4 \%$ are stunted (Shisana et al., 2013). Most South Africans seem to be meeting their dietary energy needs, but the quality of diets is of concern (Temple et al., 
2011). While rising obesity rates have been attributed to nutrition transition in urbanizing populations in low and middle-income countries (Popkin et al., 2012), they are harder to explain in rural, agrarian settings, where obesity often coexists with childhood stunting in the same households. In South Africa, chronic food insecurity where diets are energy-sufficient but low in micronutrients has been described as 'hidden hunger' (Hendriks, 2015).

Although food security is universally defined as "when all people, at all times, have physical and economic access to sufficient, safe and nutritious food to meet their dietary needs and food preferences" (FAO 1996), it is, in reality, a diverse set of experiences unique to geographical spaces and local economic conditions (Cistuli et al., 2014; Riley et al., 2014 and Barca et al., 2012). Experiences of food insecurity are widely variable and shaped by local social, economic and political environments, livelihoods and interactions with food systems (Hendriks, 2015). Rural livelihoods in South Africa entail shifting combinations of wage labour, subsistence and small-scale agriculture and access to different social protection measures (Neves \& DuToit, 2913; O'Laughlin et al., 2013). Inadequate information and highly centralized policymaking have produced one-size-fits-all strategies and policies that overlook local environments, community-level constraints and capabilities (Hendriks, 2014).

Realizing the constitutional right to food in South Africa requires food and nutrition security policies, strategies and programs based on more accurate information and greater local accountability (Hendriks, 2014; Pereira \& Ruysenaar, 2012). Former UN Special Rapporteur on the Right to Food Olivier de Schutter suggested that food and nutrition security strategies in South Africa need to be more inclusive, participatory and accountable, including communities and small producers and civil society oversight:

$[\ldots]$ in order to allow all stakeholders (from the producers to the end consumers) to arrive at a joint diagnosis of which improvements could be made to rebuild the local food system and to propose certain social innovations (DeSchutter, 2014:16).

This suggests greater inclusion of communities in the co-creation of knowledge, for example in the design, execution, analysis and dissemination of research. Participatory and inclusive food security research is an important part of the renegotiation of power in food systems, transforming people from passive consumers or beneficiaries to food citizens (Wilkins, 2005). In food democracy,

[...] all members of an agro-food system have equal and effective opportunities for participation in shaping that system, as well as knowledge about the relevant alternative ways of designing and operating the system (Hassanein, 2003:7).

More multidisciplinary, inclusive and participatory approaches to understanding hunger and malnutrition through food security research may open up a wider range of possibilities for responses in the forms of strategies and programs to address environmental, social and political determinants.

\section{Area Description}

The research project "Current rain-fed and irrigated production of food crops and its potential to meet all year round nutritional requirements of rural poor people in North West, Limpopo, KwaZulu-Natal and Eastern Cape Provinces" took place in the poorest local municipalities each of the four poorest provinces of South Africa. These were identified as Ingquza Hill in the Eastern Cape, Jozini in KwaZulu Natal, Maruleng in Limpopo and Ratlou in the Northwest (Figure 1). The selection was done using the Heath Systems Trust Deprivation Index, a measure of relative deprivation of populations derived from a set of demographic and socio-economic variables obtained from the national survey data (Day et al., 2012). All of the communities were located in what were once designated as 'homelands' or reserves for black South Africans. Following the large-scale land expropriations carried out under the 1913 Native Lands Act, which brought territorial segregation into law, the majority of black Africans were relegated to just over 7\% of South Africa's territory, and least arable land. This simultaneously made way for settler farming and generated dependency on migrant labour in the industrial and large-scale farming sectors (Bundy, 1979). The legacy of this is rural underdevelopment and shifting household livelihoods highly dependent on social protection, wage labour. Settlements are an often-crowded patchwork of household gardens, small livestock, small-scale farming, dwindling access to natural and ecosystem resources, with a few successful medium and large-scale enterprises (Hendriks, 2014). Multiple shocks and stresses have affected rural livelihoods, including the HIV pandemic, which, before the rollout of a national treatment program, decimated the working-age population in many communities, contributing to both acute and chronic food security (Misselhorn \& Hendriks, 2017). More recently, climate change, including prolonged drought, is having profound impacts on food security across the region (Thomson, et al., 2010). 


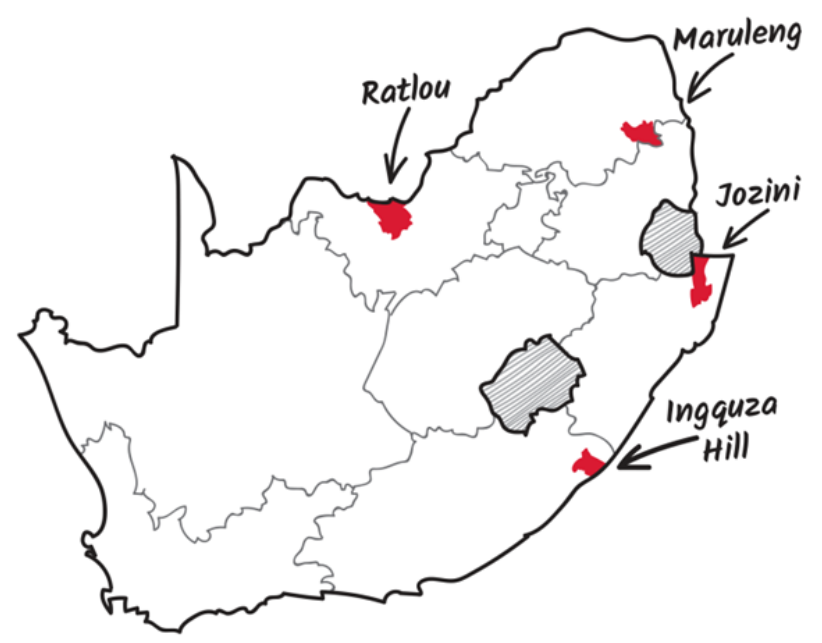

Figure 1. Map showing study areas.

The four project sites were culturally, linguistically and geographically distinctive. In each region, focus group discussions on food production, preparation and consumption, which included foods that were consumed in the past or slowly disappearing from diets. The regions had unique food traditions, which were described in rich detail in the qualitative component of the study, but these accounts were contradicted by the bland uniformity of the diets described in the household surveys.

Ingquza Hill, a Xhosa-speaking community in the Eastern Cape, is distinguished by its surrounding vast tracts of terraced farmland, formerly planted with maize and other staples, but now largely disused and sometimes eroded. Household subsistence farmers now work on small, fenced home gardens, producing vegetables and keeping small livestock. A few, usually elderly, people still use traditional ox-drawn ploughs and sledges to work the terraces, but for the most part, the terraced land lies fallow and has been this way for several decades. Subsistence agriculture predominates in Ingquza Hill, a coastal biome that is also home to dune forests, swamp forests and coastal forests that are exploited by local communities for fuel and food.

Jozini (Kwa-Zulu Natal Province) is in South Africa's tropical region and contained most of the surveyed households with somewhat larger areas crop production (more than a half hectare). Survey participants explained that extensive communal grazing was available in the past (approximately before 1990), but grazing availability has declined over the years and fewer people have their own cattle and land to cultivate, so foods formerly produced now need to be purchased. A large irrigation scheme enables year-round production in cooperative gardens of vegetables and some tropical fruits. Located near a floodplain, the community has seen a number of state-subsidized local development initiatives, including a cotton farming scheme that generated controversy for its environmental and social impacts and limited contribution to the local economy (Witt et al. 2007).

In the tropical district municipality of Maruleng, agriculture played a greater role in livelihoods than in the other study sites, with more diverse and vibrant involvement in household, subsistence and smallholder production, as well as a greater variety of crops and more involved local management of resources. A few Maruleng producers reported farming on larger private plots and produced more staples than the Eastern Cape and KwaZulu-Natal groups. Some households were farming maize on plots of up to six hectares, producing enough maize to feed their families for the entire year without the need to purchase. Their main constraints were considered to be to be inputs such as fertilizer and mechanised tillage (the use of tractors), which were considered too expensive. The Mopani District has a number of small, community-managed irrigation schemes fed by mountain springs, which are in various states of disrepair.

In Ratlou District Municipality, the two selected communities shared the same typical arid bushveld type landscape. With the exception of a few large farms, limited crop production was observed. In the focus group discussions, participants confirmed that, nowadays, only a few people engage in limited crop production, concurring with the study finding that only about $6 \%$ of households practised home gardening. Previously, many households followed the Tswana tradition of cultivating crops for household use at the masimo (traditional cultivation fields outside a Tswana village). Some of the older focus group participants in Madibogo remembered that maize was grown on large farms in the area during the time when Madibogo was part of the Bophuthatswana 
homeland. In recent years, the scale of maize production in this area has decreased to the extent that the grain silos near the railway station in Madibogo are no longer in use. Diminishing home production was attributed to low rainfall in recent years and the growing scarcity of water. Nearby rivers had dried up and only a few households had access to boreholes.

\section{Methods}

The focus of this paper is the participatory validation and interpretation of the results of a three-year study aimed to explore the consumption and production patterns of 280 rural households. This data was collected with the aim of understanding the contribution of home or smallholder grown foods to total dietary intake and nutritional requirements in some of South Africa's least food secure communities. Two panel surveys were conducted at each site - one in the drier and less agriculturally productive winter months and one in the summer months. The survey captured information about household crop production, food consumption, a range of food security indicators, and anthropometric measurements of children aged between 24 and 59 months and their female caregivers. Focus group discussions with household producers and small cooperative members were held in each community to discuss food consumption and production practices, to explore precautionary behaviour adopted when faced with food shortages and to determine whether there had been changes in food production and consumption over time. The project also generated culturally and agronomically appropriate crop recommendations for strengthening rain fed and irrigated production in the rural areas under investigation. The study concluded that households with access to irrigation for small-scale production had greater dietary diversity, with higher consumption of fruits and vegetables than those households not producing or practicing only rain-fed cultivation (Hendriks, et al., forthcoming 2018).

At the conclusion of the study in February of 2016, community stakeholders including small-scale farmers, co-operative garden members and community leaders were invited to workshops aimed at validating and interpreting the study findings within their own realms of knowledge and experience. Varying levels of literacy among the participants required presentations of numerical, quantitative data in accessible forms. A graphic designer prepared a series of posters and brochures specific to each research site. The four-page brochures contain a brief introduction to the research project and a map indicating the four districts and highlighting the one featured in the brochure; graphics presenting data on irrigation, household dietary diversity, including frequency of consumption of food over seven days and seasonal consumption of different food groups; anthropometry of adult female caregivers and children; key nutrition messages; and recommended irrigated and non-irrigated crops for summer and winter for optimal dietary diversity (Figures 1-7).

some of the focus group participants from earlier rounds of qualitative data collection were invited to the workshops. Also in attendance were some of the original survey enumerators, who were familiar with the field research and helped with facilitation and explanations of the pictographs. The main oral presentations were given in local languages (Zulu, Xhosa, Pedi and Tswana) by members of the research team or rural development workers from LIMA, a South African non-governmental organization that facilitated the research process in the four communities. All participants gave informed consent. After presentations of each set of findings, the participants were divided into groups of five or six people to discuss the research findings with the support of facilitators, after which they shared their interpretations with the group in a plenary discussion.

The discussion questions given to the groups were:

- Is the information presented an accurate depiction of the situation or context in the community?

- Are there foods in the recommended list for growing and eating that the community would not grow for reasons of preference, taste, culture?

- Are there foods in the recommended list for growing and eating that the community would not grow for reasons related to agronomic factors? And what are these factors?

- Have the foods you grow and eat changed over time - are there things that you eat less frequently or have disappeared from your diet and why?

The discussions were interpreted from local languages into English, recorded and transcribed. The analysis aimed to identify common narratives in order to preserve coherence and sequence of events. The following results are representative of the narratives that recurred during the workshops across the communities.

\section{Results}

Participants in each workshop commented that this was their first experience of researchers returning to the community to present findings and invite discussion. People needed encouragement to speak up and to challenge 
the so-called 'experts,' but once the workshop process and the data, in graphic forms, were adequately explained, there was generous participation. Graphic illustration of data used in the workshops and summaries of the discussions are presented below, according to the topics of the presentations, namely irrigation and cultivation, food consumption, nutrition outcomes and cultivation recommendations. In many cases, there was unanimous agreement on the accuracy of the data; usually this was accompanied by affirmative comments or explanations. In instances where participants contested the research findings they offered explanations for why they agreed or disagreed. Following the validation results are further community interpretations of the data, some of which are presented in their longer narrative forms.

\subsection{Validation}

\subsubsection{Crops and Irrigation}

Figure 2 illustrates that nine in ten surveyed households in Ingquza Hill and Jozini were engaged in crop production $(90 \%)$. More than eight out of ten $(82 \%)$ of the surveyed households in Maruleng were engaged in cropping. Very few households (four) surveyed in Ratlou were engaged in home gardening. All community gardens were irrigated, while $78 \%$ of farmland (usually plots of more than $1 / 2$ hectare) and $75 \%$ of school gardens were irrigated. Just less than half $(47 \%)$ of home gardens were irrigated. Irrigation was taken to mean any application of supplemental irrigation - from overhead sprinklers using pumps, flood irrigation from irrigation schemes, municipal water from taps or rain tanks (seen at many Ingquza Hill homesteads), to using a hose pipe or watering can with water drawn from rivers, tributaries, springs, wells, boreholes and tanks.

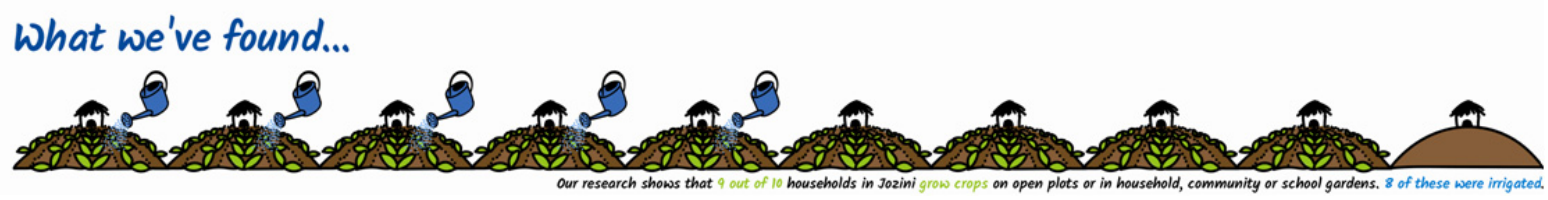

Figure 2. Presentations of households cultivating and irrigating data

The irrigation research findings (Figure 2) were affirmed by participants in Ratlou and Maruleng but contested by those in Jozini and Ingquza Hill. Participants in the Jozini workshop explained that fewer people were irrigating their crops than reported because the large local irrigation scheme fed by the Pongolapoort dam had been in disrepair for some time. In Ingquza Hill, participants suggested that the only households that irrigated cultivated crops were those who produced to sell, for example to the school feeding scheme. They also pointed out that hand irrigation was most common, but very fewer people were doing this this due to the scarcity of water in prevailing drought conditions.

A general trend towards fewer household cultivating in all communities was explained by drought or diminishing rainfall over a long period of time as well as restricted or difficult access to surface water. Otherwise, the people who did not plant might also be child-headed households or 'lazy people.' It was alleged by different participants in each of the communities that the introduction of social grants (means-tested government cash transfers for the elderly, disabled and support of young children), had edged people towards abandoning cultivation altogether.

\subsubsection{Food Consumption Patterns}

The survey results showed that the majority of households consumed foods from only four to eight of 14 food groups (Figure 3). Only $32 \%$ of the households surveyed had consumed food from eight or more food groups in the previous day in summer, while $20 \%$ of the households had consumed food from these food groups in the previous day in winter. 

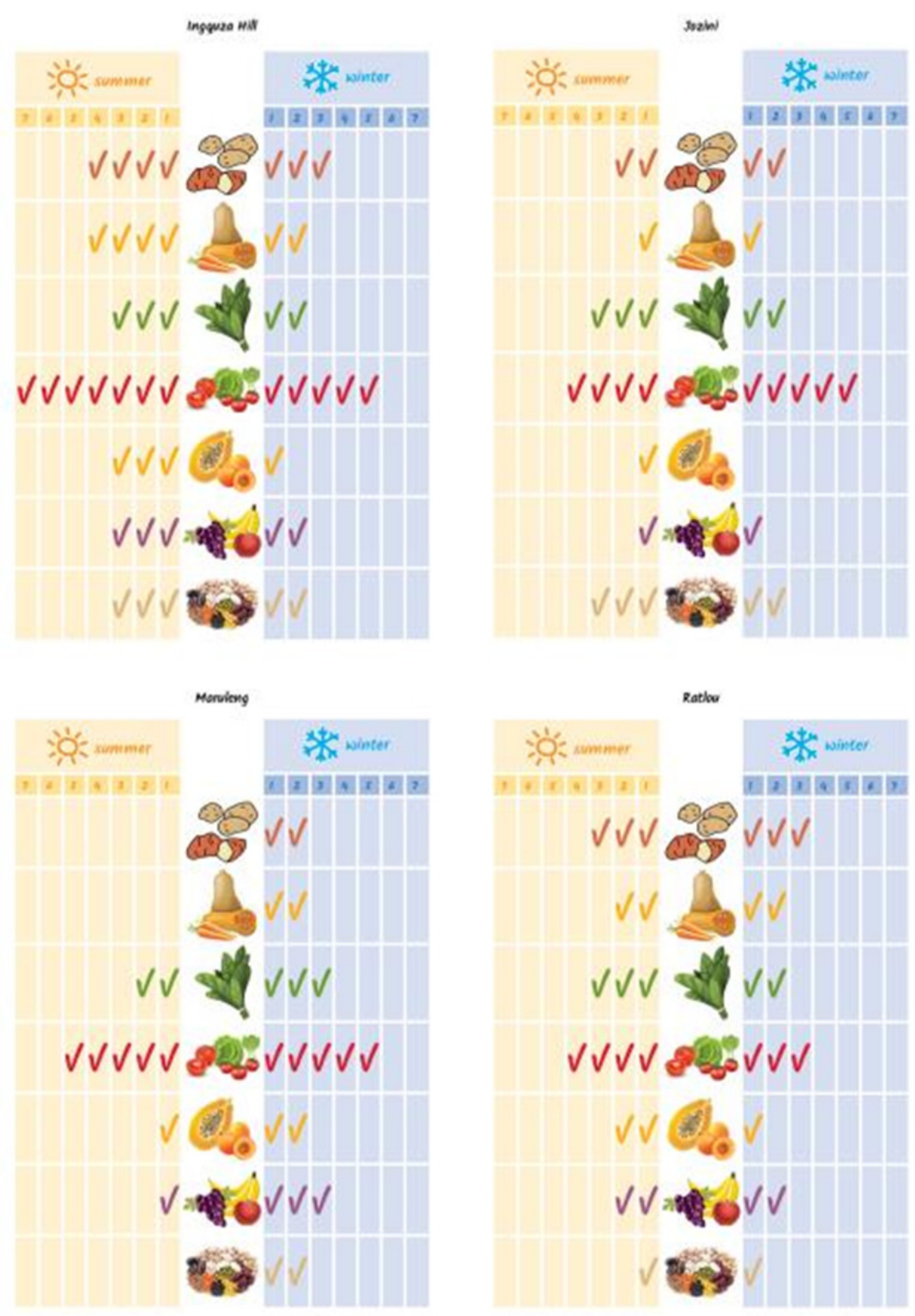

Figure 3. Presentation of dietary diversity data

The consumption findings were found to be accurate by the Ratlou participants, who explained that the long distance from markets and supermarkets meant infrequent access to fresh fruits and vegetables. Some people lived more than 100 kilometers from the closest small town and traveling was expensive (roughly R125 or around US\$ 10.00 per return trip by public transport). There were few back yard gardens because water was not available in this arid region, but even where boreholes and municipal supplies provided water, few people grew food. It was suggested that climate change has made growing unpredictable because of diminishing rain and more intense heat, which also made it more difficult to preserve perishable food. It was suggested that even in the shops food sometimes rots for this reason.

Participants in Maruleng agreed with the research findings and explained the lack of dietary diversity could be attributed to the shortage of money to buy different foods. Maize meal was usually the only food that could be made to last the whole month after other items ran out.

Participants in Jozini also agreed with the findings presented and explained that most of the vegetables they ate were grown close to the dam (reservoir) or river, where hand irrigation made year-round production possible. Otherwise, vegetables were not eaten because they were too expensive to buy. The communities relying on rain-fed production did not eat many fruits and vegetables in summer because they could no longer be grown in 
this region owing to drought and were too costly to purchase. Fruits such as bananas, which are widely cultivated commercially in the region, were also too expensive for households to grow or purchase.

Meals in all communities consisted mostly of starch (maize meal) with daily consumption of refined sugar. People across the communities reported difficulties in managing their household grocery supplies and serving diversified meals because 'some foods are finished sooner than others' and so households relied on only starch-based staples for most of the month

\subsubsection{Nutritional Status}

The Body Mass Index (BMI) of female caregivers of small children in the surveyed households, represented in Figure 4, was calculated as:

$$
\frac{\text { Weight in kg }}{\text { Height in meters }}{ }^{2} \text {. }
$$

Just over one in five of the female caregivers (22\%) was overweight and $37 \%$ were classified as obese (BMI over 30 ). Combined, the proportion of overweight and obese female caregivers was $59 \%$. Proportionately fewer cases of underweight women were found, although 19\% of the caregivers in Maruleng were underweight.
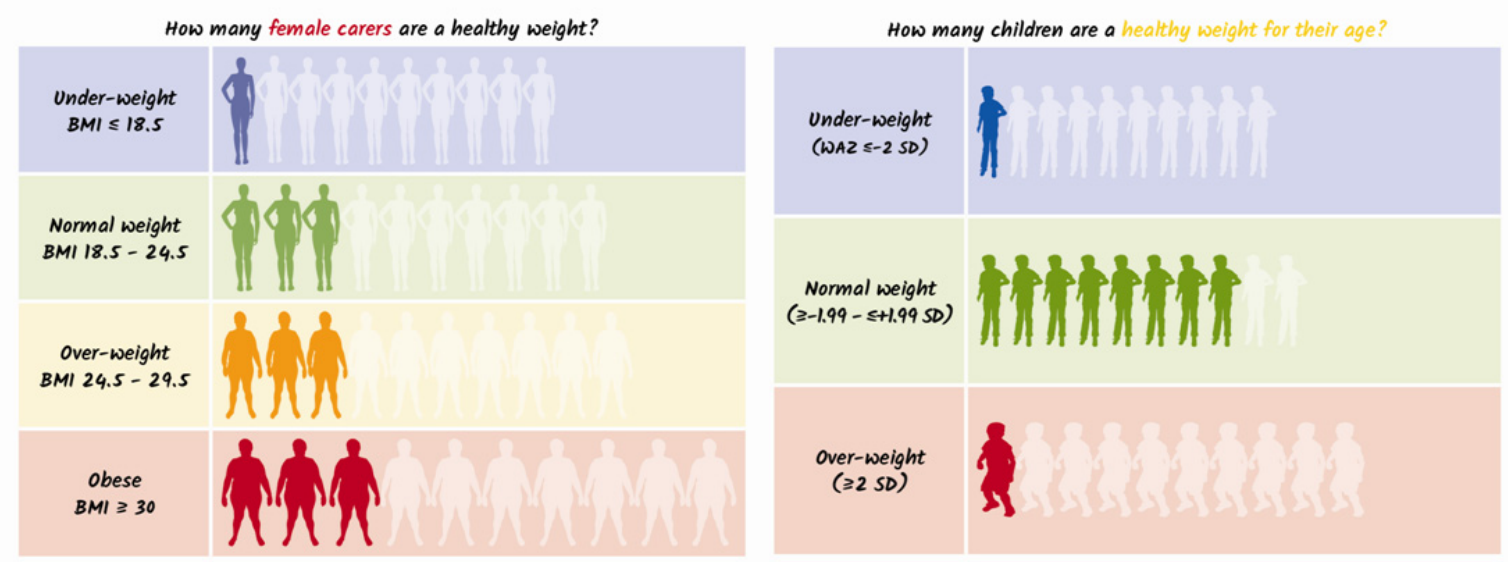

Figure 4. Validation presentation of anthropometric data, female caregivers

The rates of stunting represented in Figure 5 are based on measures of height for age and indicated by z-scores $\leq 2$ standard deviations below the norm, was $24 \%$ overall among children of 24 to 59 months generally confirmed the national statistics for this indicator of deprivation. Stunting was considerably lower in Maruleng, where many more rain-fed crops were grown than at the other sites. Overall, $15 \%$ of the children were overweight.
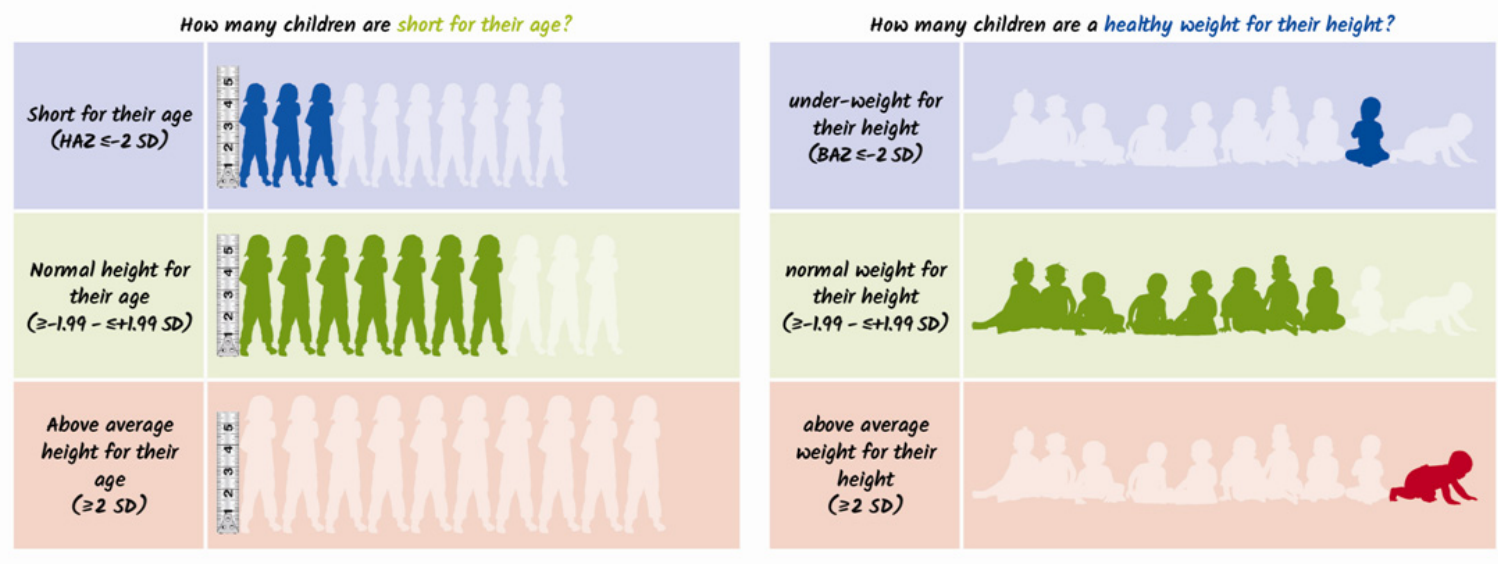

Figure 5. Validation presentation of child anthropometric data 
The participants in Ratlou agreed with the findings on the nutritional status of young children and their caregivers. They explained that poor nutrition resulted from a lack of farming. Producing crops was not possible due to the inaccessibility of resources, including land, water, implements, seed and funds for other inputs, all of which determined the availability of food. They also blamed shocks and stresses such as crime, sickness, death, floods and drought. They explained that there used to be more dams (small, human-made surface water reservoirs) in the area when the rains were better; it was suggested that the clouds 'don't really rain anymore.' Participants also suggested that people eat the wrong foods. They also claimed that there are 'a lot of chemicals in store-bought foods that result in people being overweight, sickly and generally in poor health'. When people prepare their food incorrectly, it destroys the nutrition and the body cannot take up nutrients properly. Some households tend to buy the 'wrong foods or cannot afford to buy healthy ones'. Families are large and feeding so many mouths is unaffordable. Some claimed, on the other hand, that sometimes stunting or overweight simply reflects the body types people are born with, suggesting that these conditions are not dependent on nutrition and are beyond their control.

The participants in Maruleng considered the nutrition findings to be accurate and blamed caregiver obesity and child stunting on the inability to grow or purchase a variety of healthy foods. They also suggested that obesity could also be passed along from mother to child when mothers eat too much.

The Jozini participants found the results accurate, offering a number of explanations for coexisting obesity and stunting. They stated that obese people ate too much junk food such as potato chips, but they also ate too much meat, a lot of cooking oil or just too much food in general. They were also no longer working in the fields as much and did not exercise. Children were overweight because of a poor diet with too many carbohydrates, like their mothers, but short for their age mostly because they resembled their short fathers. Women tended to be underweight, it was explained, when they didn't have water to irrigate and couldn't eat fresh vegetables, but it was agreed that most people didn't balance their diets and ate too much starch.

The participants in Ingquza Hill agreed with the overweight and obesity data, which was explained by people eating too much starch and not having balanced diets because they did not have correct information on nutrition. They disagreed with the numbers of underweight children, suggesting that there were more of them in the community, so perhaps the researchers had missed many of the households with sick people. They also claimed that there are more tall children than the survey revealed, suggesting that one child could be taken from the 'short for age' graphic and added to the 'tall for age' as a way of making the research findings more accurate.

\subsubsection{Crops Not Grown or Eaten for Agronomic or Cultural Reasons}

The study recommended crops based on their potential to improve nutrition, indicating where they would grow, and whether irrigation was required. The workshop presentation of recommended crops is shown in Figure. 6 . While no particular cultural reasons were given for not growing particular crops, it is probable that in some areas, crops have never been grown because they are simply not preferred, nor have they been promoted or spontaneously taken up. The main reasons given for not growing crops, though, were water-related, either insufficient rainfall or barriers to accessing irrigation and water sources. Participants in all four workshops suggested that crop size and diversity have been dwindling steadily over the years due to diminishing rainfall.

The recommendations for Ratlou were contested on the grounds that virtually none of the recommended crops could be grown due to drought and a lack of water for irrigation. There were even drinking water shortages, so to even think of planting crops that need water was impossible. All the participants in Jozini agreed that all the recommended crops needed irrigation except for legumes, loquat, melons and amadumbe (taro) and sometimes pumpkins and butternut squash, depending on the area. The Ingquza Hill participants said the findings were not accurate because all of the recommended crops needed supplementary irrigation due to the drought, except for fruit trees. Crops like potatoes, beetroot and pineapples were not grown in Maruleng because of water shortages. In the Maruleng discussion it was suggested that there are some people who are allergic to foods such as tomatoes and peanuts and would not grow or consume these. 


\section{What we recommend...}

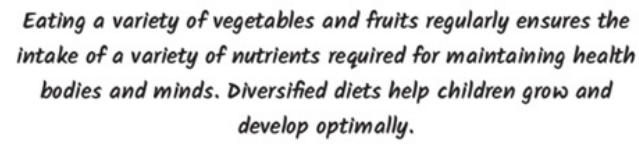

Eating a variety of vegetables and fruits regularly ensures the intake of a variety of nutrients required for maintaining health bodies and minds. Diversified diets help children grow and develop optimally.

Diets can be improved by including the following foods or increasing the number of times in a week these foods are consumed. Growing these foods for home consumption will improve the diets of small children and adults.

The crops in the table below are able to grow in Jozini.

\begin{tabular}{|c|c|c|c|}
\hline Food group & Crop & $\begin{array}{l}\text { Can provide } \\
\text { food: }\end{array}$ & $\begin{array}{c}\text { Supplemental } \\
\text { irrigation } \\
\text { needed }\end{array}$ \\
\hline \multirow{3}{*}{$\begin{array}{c}\text { White roots and } \\
\text { tubers }\end{array}$} & Amadumbe & & \\
\hline & Potato & & \\
\hline & Sweet potato & & \\
\hline \multirow{8}{*}{$\begin{array}{l}\text { Orange- and } \\
\text { red-fleshed } \\
\text { vegetables }\end{array}$} & Beetroot & & \\
\hline & Tomato & & \\
\hline & Carrots & & \\
\hline & $\begin{array}{l}\text { Pumpkin I } \\
\text { Butternut }\end{array}$ & & \\
\hline & Gem squash & & \\
\hline & $\begin{array}{l}\text { Orange-fleshed } \\
\text { sweet potato }\end{array}$ & & \\
\hline & $\begin{array}{l}\text { Hubbard } \\
\text { squash }\end{array}$ & & \\
\hline & Pumpkin & & \\
\hline \multirow{6}{*}{$\begin{array}{c}\text { Dark green leafy } \\
\text { vegetables }\end{array}$} & Broccoli & & \\
\hline & $\begin{array}{l}\text { African leafy } \\
\text { vegetables }\end{array}$ & & \\
\hline & Swiss Chard & & \\
\hline & Beetroot leaves & 乘 & \\
\hline & $\begin{array}{l}\text { Pumpkin } \\
\text { leaves }\end{array}$ & & \\
\hline & $\begin{array}{l}\text { Cowpea and } \\
\text { legume leaves }\end{array}$ & & \\
\hline
\end{tabular}

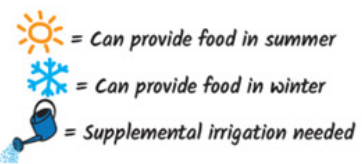

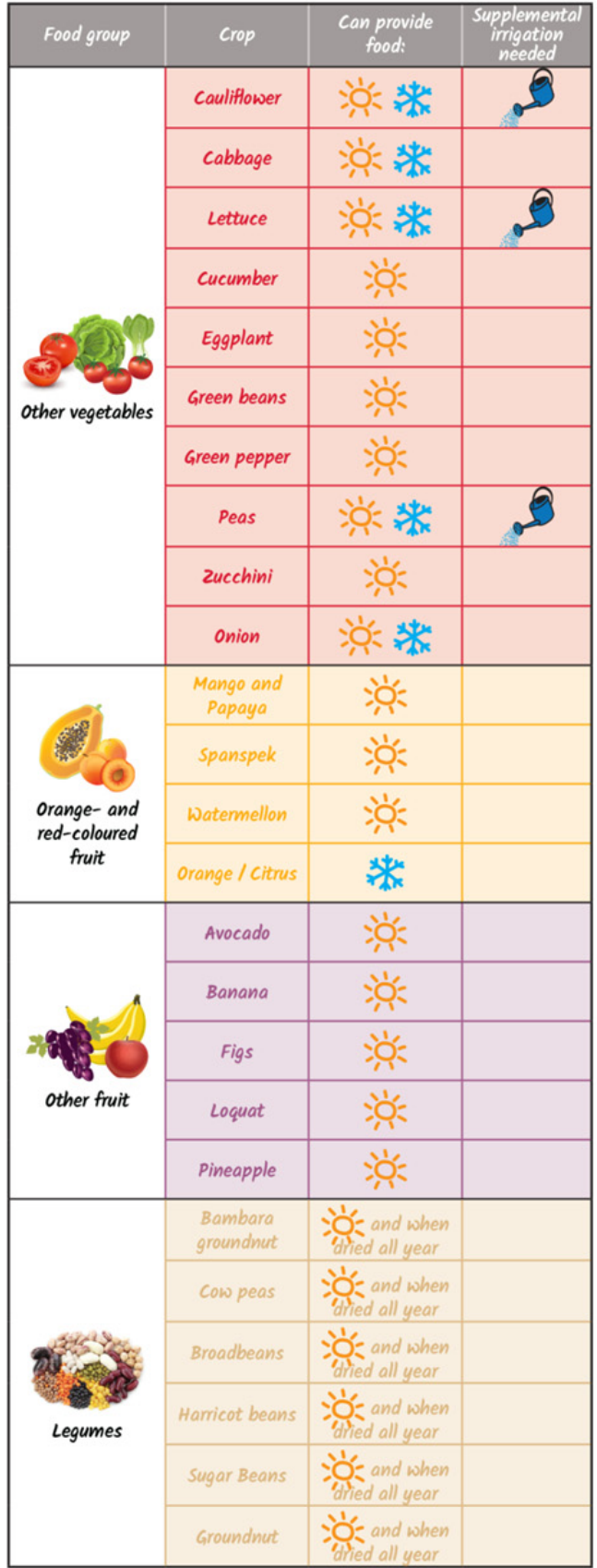

Figure 6: Validation presentation of recommended crops

\subsection{Further Community Interpretations}

In the shift from research subjects to co-creators of knowledge, the workshop participants offered interpretations of the study results that crossed the boundaries of the traditional disciplines of nutrition, agriculture and food security, suggesting pathways between social and environmental changes and health that grounded the research data their own experiences and realities. Figure 7 shows the key messages from the research, which were presented last in the workshops. Communities interpreted these with causal explanations but also raised many concerns and questions about environmental changes, food accessibility and food safety that were thought to be affecting health. 


\section{Key messages...}

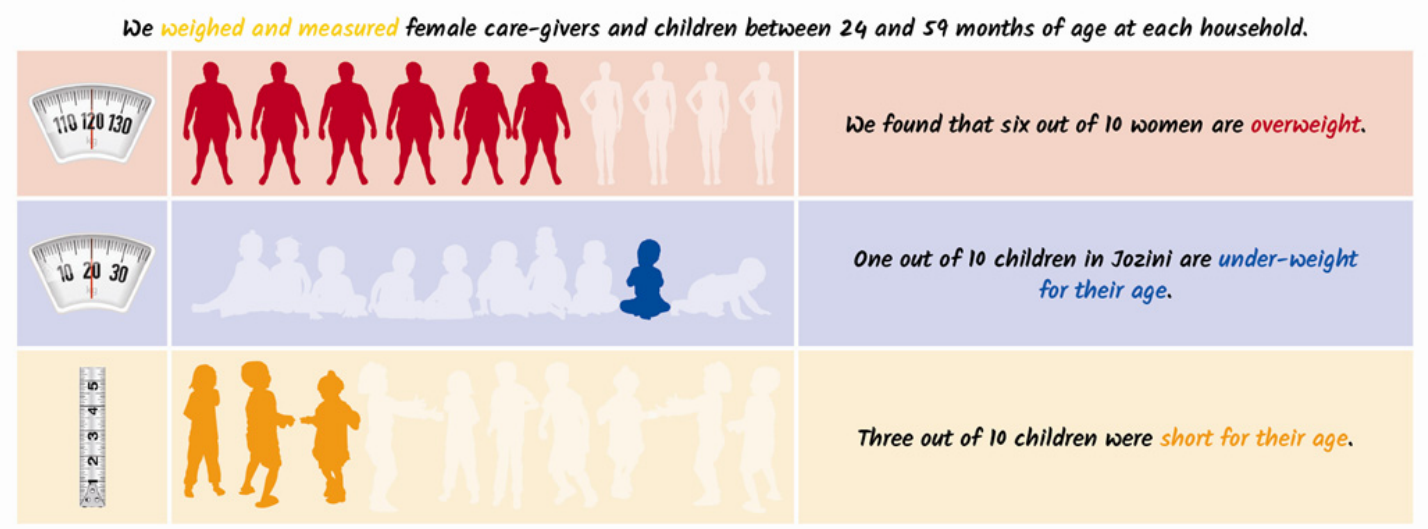

This shows these children have been under-nourished.

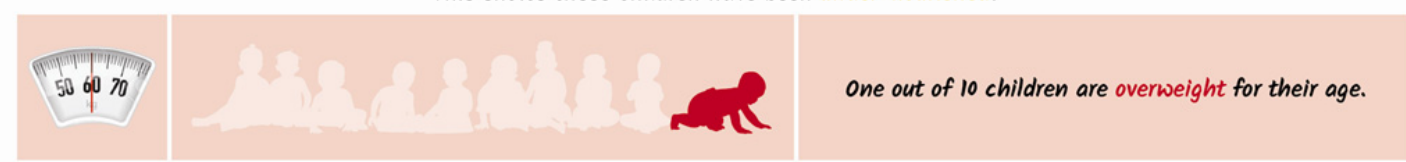

This shows that these children are not eating balanced and healthy diets.

We found that households that grow crops eat fresh vegetables and fruits more often than those who do not grow crops. They also eat more eggs and fish than households that do not grow crops.

We also found that households that irrigate enjoy a more diverse diet, eating fresh vegetables and fruits more often than those who do not irrigate their crops. They also eat more meat, eggs, fish and dairy products than households that do not grow crops or irrigate.

Improvements in the diets of all household members is necessary for improved nutrition, health and productivity.

Figure 7. Validation presentation of key messages

The term 'climate change' was used frequently in relation to changing crop production and recurred in explanations of the findings on production, consumption, nutrition and crop recommendations. While 'climate change' was sometimes used interchangeably with 'drought,' it was apparent that the phenomenon being described was not a single season of low rainfall. People also described changes over decades in vegetation, especially forest, veld (wild grasslands) and grazing lands, the availability of, and accessibility to, surface water, irrigation water and water for household consumption.

Other changes have occurred in access to social protection and entitlements to land and water. Some, like the rollout of social grants, have affected all the communities. Others have been affected by more localized changes such as major developments impacting land use. People have responded to multiple, concurrent changes over time with adaptations to their livelihood strategies, farming practices and food procurement and consumption patterns. Some or all of these factors emerged in the communities' interpretations of data on production, dietary diversity and nutrition outcomes described below.

Across the study sites, there was the perception that diets were more diverse and healthier in the past:

"We used to produce many things like nuts, watermelon, pumpkins and others - there were locusts and other foods. There is a lack of rain and we don't gather these things any more. The diet was more diverse and people were healthier. We also had access to medicinal herbs such as ditlomma mago, but this is no longer around. This was our medication for diabetes and hypertension. [...] People were eating wild herbs and were healthy all the time. Even the animals were healthier." [Jozini workshop participant]

Climate change, drought, or lack of rain were frequent explanations for the shift away from more wholesome, home-grown and prepared foods to shop-purchased, mass-produced products and this was linked to nutrition and more general health outcomes. The stunting and obesity levels indicated by the data were often attributed to shop-purchased, refined carbohydrate-based diets, consisting largely of maize meal and white sugar, with fewer fresh fruits and vegetables, both wild and cultivated, either available or accessible:

"The combination of foods in a plate, all starch, people do not have a good plate in front of them. Management of 
the household groceries is a problem - they might by all the foods but they are not combining them or not used in the appropriate quantities, some get finished earlier than it is supposed to, then they rely only on the staples." [Ratlou workshop participant].

"Even the fruit trees are not giving enough because of climate change - oranges have reduced, the spinach is no longer giving big leaves. Some of the traditional crops are no longer grown because of the changes. They used to rely on rain, even maize used to be grown on a larger scale but no longer grown and now there are only small vegetable plots." [Jozini workshop participant]

Knowledge and diversity of wild-gathered foods and livestock husbandry was influenced by changes in weather and ecosystems. This caused changes in food consumption patterns, and eventually food preferences. Lost harvesting, production and preservation knowledge and practices relate to both vegetable and animal food sources:

"We did not have fridges but we had methods of preserving our food and cooling with a pot underground. We made sour and fresh milk. To sour the milk we would use cowhides to make Lekuka for fermenting milk. [...] before this [modern] civilization, the main dish was sorghum porridge prepared with fermented sorghum meal and the most common relish [condiment] with this was milk - raw or soured. In summer or during rain, it would be indigenous leafy vegetables but more and more they are difficult to find." [Ratlou workshop participant]

The disappearance of traditional, small-scale farming and food knowledge and growing reliance on chemical agricultural inputs and biotechnology raised concerns health, safety and sustainability:

"We had ways of preserving food to keep diseases away, for example using smoke. Now the agricultural products are full of poison. The food is full of pesticide and this makes people unhealthy. People cannot afford to farm because they depend on chemicals and GMO seeds. They pay and pay and owe money and still cannot produce enough to eat." [Ratlou workshop participant].

At the same time the proliferation of easily prepared and processed foods through retail expansion into rural areas were thought to be turning preferences towards more modern foods and, alongside other lifestyle ambitions, away from the ardours of farming. Fast food from global franchises is readily available even in the poorest districts, close to the supermarkets where people purchase their staples. Unlike their urban counterparts, though, many rural people simply do not have the income to afford to eat much of it. But even if it is often more aspirational than affordable, 'junk food,' as it was referred to by some, makes a notable contribution to unhealthy lifestyles:

[...] obese people a people eat junk food such as potato chips, but also too much meat and a lot of cooking oil or just too much food in general. They are no longer working in the fields, do not exercise and eat too much. [Jozini workshop participant]

In each of the workshops, there was at least one mention of the role of social grants (mean-tested cash transfers), in changing diets and even lifestyles. Although it was suggested that households not producing were among the most vulnerable and unable to farm, some participants thought social grants could be a disincentive to farming:

"Fewer people are planting, but the ones who are not are likely to be of child-headed households or lazy people. Social grants have also caused people to abandon cultivating." [Jozini workshop participant]

\section{Discussion}

The participatory validation and interpretation of the data from this multidisciplinary food security research project generated unique, localized interpretations of food production, consumption and nutrition outcomes as they are experienced by people living in the most economically deprived regions of South Africa. These interpretations are linked by a broader, national, historical narrative of shifting livelihoods created by land dispossession and the creation of homelands, migrant labour, political change, democratic reforms, new social protection measures and the far-reaching effects of globalization and climate change. These phenomena have exerted pressures on local environments, livelihoods and cultures, impacting nutrition and food security along pathways that are locally unique.

The high levels of obesity found among adult female caregivers and of stunting among children were readily linked by the validation workshop participants to changes in the local environment. These changes were observed as unpredictable rainfall, reduced water availability and shifting vegetation patterns over an extended period, which many people described as 'climate change. People saw this to be affecting health along a pathway of diminishing dietary diversity, growing reliance on 'unhealthy' purchased food. When there were more abundant and predictable rains, people recalled, there was greater crop diversity, more wild foods to be gathered, more livestock producing meat and milk and even different staples such as sorghum, which is still considered a 'traditional' grain, healthier than maize.' 
Declines and changes in food production were not the sole explanation for dietary and health changes, however. Certain crops that may have been suitable twenty or more years ago are no longer viable and wild plants and animals no longer thrive. Local and more traditional foods are seen to have been replaced with 'GMO' seeds, commercial fertilizers and pesticides, which are thought to be expensive and unsustainable. The inputs and products of modern agriculture were sometimes mistrusted because they exposed people to chemicals and produced food suspected to make people weaker and more vulnerable to poor health.

Participants did not see these changes in isolation from other social and political changes. In addition to the introduction of social grants, there have been changing work opportunities and the arrival of large supermarket and fast food chains in rural areas (Igumbor, et al. 2014). Although these have undoubtedly influenced food consumption patterns, this is not necessarily a straightforward trade-off between producing and buying food. Historically, trading stores (rather than supermarkets) played an important in role food availability in the former homelands and purchased food has contributed to diets (Pereira et al. 2012). People also continue to produce and harvest certain foods for mainly cultural and ceremonial use, and rural food systems may be valued for more than purely economic reasons (Ngcoya \& Kumarakulasingam, 2017).

Cash incomes from urban labour and social grants are likely subsidizing inputs for smallholder and subsistence farming. It is quite possible that grant money is used by pensioners (who are often also child caregivers, receiving both old-age and child care payments) to subsidize household food production. Elders more often have the knowledge and aptitude for cultivation and might be spending some of their income on seeds and tools or investments in small livestock. The pensioner / household-head is a common role in South African households where working-age parents of young children move to towns and cities in search of paid employment. The lack of enthusiasm among youth for farming was seen to be contributing to a decline in subsistence production among the participants.

All these descriptions of change - shifts local environments, in farming and food consumption - serve to ground wider, global phenomena such as food insecurity, nutrition transition and climate change in local environmental, social and political contexts. Rural livelihoods are complex and shifting and high-level food security diagnoses often lack the insights necessary to inform effective support programs. Local narratives, on the other hand, bring the elements together in cohesive and place-specific ways, suggesting that a wider, multi-disciplinary food security policy lens is needed to capture the diversity of challenges and possibilities of rural South Africa.

\section{Conclusion}

The results of this validation and interpretation exercise highlight a sense among the participants that change is beyond the control of ordinary people, seeming to bring to the rural poor all the hazards and none of the benefits of modernization. Changing local environments and weather, rising food prices, political turmoil, the expanding presence of retail chains, migration and the effects of the HIV epidemic have created an atmosphere of deep uncertainty. Besides the health consequences of food insecurity, these local conditions may be also exacerbating the subjective experiences of hunger. The notion that modern crops may actually be poisoned by the use of chemical fertilizers, pesticides and genetic modification is a source of concern among the rural agrarian people in who participated in this study. The disappearance of more diverse, traditional diets and farming practices was clearly connected with adverse climate changes and poor human health. These suggest a need for more participatory research and knowledge translation around food safety, farming methods and nutrition for rural people.

Additional areas for research might include traditional food knowledge and localized agro-ecological practises that might enhance resilience and sustainability. Given the varied and unpredictable local environmental and socio-economic impacts of climate change, it has become imperative to explore alternative, more resilient production methods and where necessary, revise pedagogical models of agricultural extension and update the overall agronomic knowledge base. This should occur in conjunction with an exploration of water harvesting methods and with removing existing technical and political obstacles to access to water faced by subsistence and smallholder producers.

For social protection, understanding the interplay between different livelihood components, for example combinations of reliance on social grants, food production and other incomes is of further interest, given the possibility that cash incomes are subsidizing home or small-scale production and these might be contributing to healthier food consumption patterns. In this case, better support for small scale and subsistence production in terms of inputs, extension and irrigation could potentially free up cash incomes for other household expenses, including food, health care and education. 
The retail sector, with its unprecedented control over food affordability and accessibility, is also worthy of further investigation for its potential role in food security. There is year-round production of fresh produce that is both exported and available in South African supermarkets, but this is often unavailable to the poor, who subsist on a poor quality diet that barely meets energy requirements. Food prices in South Africa have risen sharply in recent years, a trend that will only worsen with drought, fuel price increases and currency devaluation, while social grants remain static.

Finding new ways to bring citizens into food security policy making could have both political and technical value. With the exchange of information that took place in these validation workshops, civil society members, researchers, food producers, government extension and social services workers and a few local administrators, albeit on a small scale, became 'food citizens' engaged in creating a better understanding of food security. Given the strides made through democratic transformation towards the achievement of other constitutionally-guaranteed rights such as health and education, the time may have also come for food democracy. For this to come about policymakers need to recognize citizens as partners, and not simply beneficiaries. Conventional food security analyses generate data, which when aggregated and seen outside local contexts, leads to broad conclusions. Concurrent childhood stunting and adult obesity, for example, can suggest a number of possible dietary patterns, but localized information on what people eat and how they procure, produce and consume food is needed to overcome barriers and constraints to food security. Further grounding this information in local realities and experiences using participatory methods engages people in the diagnosis of their own food security challenges. Food insecurity is a complex social problem that cannot be addressed by a single discipline. Assessing, measuring and designing interventions to mitigate food insecurity is an evolving, trans-disciplinary field that can benefit greatly from co-creation of knowledge in a diverse stakeholder field.

\section{Competing Interests Statement}

The authors declare that there are no competing or potential conflicts of interest regarding the publication of the paper.

\section{References}

Barca, F., McCann, P., \& Rodríguez-Pose, A. (2012). The case for regional development intervention: Place-based versus place-neutral approaches. Journal of Regional Science, 52(1), 134-52. https://doi.org/10.1111/j.1467-9787.2011.00756.x

Bundy, C. (1979). The Rise and Fall of the South African Peasantry. London: James Currey.

Cistulli, V., Rodríguez-Pose, A., Escobar, G., Marta S., \& Schejtman A. (2014). Addressing food security and nutrition by means of a territorial approach. Food Security, 6(6), 879-94. https://doi.org/10.1007/s12571-014-0395-8

Day, C., Barron, P., Massyn, N., Padarath, A., \& English, R. (2012). The District Health Barometer 2010/2011. Durban: Health Systems Trust. https://doi.org/10.1007/s12571-014-0395-8

De Schutter, O. (2014). Report of the special rapporteur on the right to food, Olivier de Schutter. Final report: The transformative potential of the right to food. Human Rights Council of the United Nations. Http://www. Srfood. Org/images/stories/pdf/officialreports/20140310_finalreport_en. Pdf 2014.

FAO (Food and Agriculture Organisation) (1996). Rome declaration on world food security. World Food Summit, 13-17, November, Rome, FAO.

Hassanein, N. (2003). Practicing food democracy: A pragmatic politics of transformation. Journal of Rural Studies, 19(1), 77-86. https://doi.org/10.1016/S0743-0167(02)00041-4

Hendriks, S. (2014). Food security in South Africa: Status quo and policy imperatives. Agrekon, 53(2), 1-24. https://doi.org/10.1080/19320240802244215

Hendriks, S. L. (2015). The food security continuum: A novel tool for understanding food insecurity as a range of experiences. Food Security, 7(3), 609-19. https://doi.org/10.1007/s12571-015-0457-6

Heywood, M., (2009), South Africa's treatment action campaign: combining law and social mobilization to realize the right to health. Journal of Human Rights Practice, 1(1), 4-36. https://doi.org/10.1093/jhuman/hun006

Igumbor, E. U., Sanders, D., Puoane, T. R., Tsolekile, L., Schwarz, C., Purdy, C., ... Hawkes, C. (2012). "Big food," the consumer food environment, health, and the policy response in South Africa. PLoS Med, 9(7), 1001253. https://doi.org/10.1093/jhuman/hun006

Lang, D. J., Wiek, A., Bergmann., M., Stauffacher, M., Martens., P., Moll, P. et al. (2012). Transdisciplinary 
research in sustainability science: Practice, principles, and challenges. Sustainability Science, 7(1), 25-43. https://doi.org/10.1007/s11625-011-0149-x

Misselhorn, A., \& Hendriks, S. (2017). A systematic review of sub-national food insecurity research in south africa: Missed opportunities for policy insights. PloS One, 12(8). https://doi.org/10.1371/journal.pone.0182399

Ngcoya, M., \& Kumarakulasingam, N. (2017). The Lived Experience of Food Sovereignty: Gender, Indigenous Crops and Small-Scale Farming in Mtubatuba, South Africa. Journal of Agrarian Change, 17, 480-496. https://doi.org/10.1111/joac.12170

Neves, D., \& Toit, A. (2013). Rural livelihoods in South Africa: Complexity, vulnerability and differentiation. Journal of Agrarian Change, 13(1), 93-115. https://doi.org/10.1111/joac.12009

O'Laughlin, B., Bernstein, H., Cousins, B., \& Peters, P. E. (2013). Introduction: Agrarian change, rural poverty and land reform in South Africa since 1994. Journal of Agrarian Change, 13(1), 1-15. https://doi.org/10.1111/joac.12010

Pereira, L. M., \& Ruysenaar, S., (2012). Moving from traditional government to new adaptive governance: The changing face of food security responses in South Africa. Food Security, 4(1), 41-58. https://doi.org/10.1007/s12571-012-0164-5

Popkin, B. M., Adair, L. S., \& Ng, S. W. (2012). Global nutrition transition and the pandemic of obesity in developing countries. Nutrition Reviews, 70(1), 3-21. https://doi.org/10.1111/j.1753-4887.2011.00456.x

Shisana, O., Labadarious, D., Rehle, T., Simbayi, L., Zuma, K., Dhansay, A., ... SANHANES-1 Team (2013). South African National Health and Nutrition Examination Survey (SANHANES-1). Cape Town: HSRC Press. Retrieved from http://www.hsrc.ac.za/uploads/

Steyn, N. P., Labadarios, D., Maunder, E., Nel, J., Lombard, C., \& Survey, D. O. T. N. F. C. (2005). Secondary anthropometric data analysis of the national food consumption survey in south africa: The double burden. Nutrition, 21(1), 4-13. https://doi.org/10.1016/j.nut.2004.09.003

Swinburn, B. A., Sacks, G., Hall, K. D., McPherson, K., Finegood, D. T., Moodie, M. L., \& Gortmaker, S. L. (2011). The global obesity pandemic: Shaped by global drivers and local environments. The Lancet, 378(9793), 804-14. https://doi.org/10.1016/S0140-6736(11)60813-1

Temple, N. J., Steyn, N. P., Fourie, J., \& De Villiers, A. (2011). Price and availability of healthy food: A study in rural South Africa. Nutrition, 27(1), 55-8. https://doi.org/10.1016/j.nut.2009.12.004

Wilkins, J. L. (2005). Eating right here: Moving from consumer to food citizen. Agriculture and Human Values, 22(3), 269-73. https://doi.org/10.1007/s10460-005-6042-4

Witt, H., Patel, R., \& Schnurr, M. (2007). Can the poor help GM crops? Technology, representation \& cotton in the makhathini flats, south africa. Review of African Political Economy, 33(109), 497-513. https://doi.org/10.1080/03056240601000945

\section{Copyrights}

Copyright for this article is retained by the author(s), with first publication rights granted to the journal.

This is an open-access article distributed under the terms and conditions of the Creative Commons Attribution license (http://creativecommons.org/licenses/by/4.0/). 